\title{
Cheaper HIV/AIDS drugs coming
}

Legislation designed to provide developing countries with cheaper drugs to treat HIV/AIDS and other illnesses received royal assent May 14, and is scheduled to take effect this fall.

The legislation - now named the Jean Chrétien Pledge to Africa Act - amends the Patent Act and the Food and Drugs Act to allow developing nations to import less expensive $\vec{n}$ generic versions of brand-name patented drugs. Under the new law, the drugs must be used for public health emergencies only, including fighting HIV/AIDS, malaria and tuberculosis.

Nongovernmental organizations, including Médecins Sans
Frontières and the Canadian HIV/AIDS Legal Network, supported the legislation but decried the narrow list of medications it allows generic companies to manufacture and export. They had asked the federal government not to list medications at all, since getting new drugs on the list is difficult and time-consuming.

In other pre-election developments:

- Funding is doubled for the Canadian Strategy on HIV/AIDS, which will grow over 5 years to $\$ 84.4$ million annually;

- Canada will contribute $\$ 100$ million to the WHO's " 3 by 5 " initiative to treat 3 million

\section{Human Resources}

\section{'Playing God' during labour disputes causes stress}

Strikes in BC and Newfoundland and Labrador that forced doctors to make tough decisions in cancelling surgeries have left both systems struggling to recover.

During the 8-day strike beginning April 26 in BC, hospitals cancelled 5300 day and inpatient surgeries, 700 MRIs, $2500 \mathrm{CT}$ scans and tens of thousands of lab tests, the Health Ministry says.

The strike by 40000 members of the Health Employees Union was volatile but brief. The province legislated staff, from cleaners to licensed practical nurses, back to work.

In Newfoundland and Labrador, where a strike by 20000 civil servants lasted a gruelling 27 days in April, doctors coped by consulting with one another when they had to make the same kind of difficult decisions as their BC colleagues.

Urgent cases "are easy to decide," said Susan King, president of the Newfoundland and Labrador Medical Association. Delaying a knee replacement is "easy to live with." For doctors, the nightmares lay in between, when they had to decide whether to cancel the bowel surgery of a cancer patient. They live with the uncertainty of not knowing to what extent such delays affected outcomes.

"We really don't know if a delay in surgery hurt," King says. "If it's one week or the next, it's of little consequence. But when it gets into 4 weeks, we never know. And we will always have that doubt."

That uncertainty prompted one group of $\mathrm{BC}$ doctors to plead with workers to return during the strike. "We're making decisions where we are being asked to play God," Dr. Tom Ehlen, a Vancouver obstetrician and gynecologist, told a news conference.

With all non-emergencies forced off the schedule, doctors had to decide which patients would receive treatment, says Dr. Peter Hill of the Fraser Health Authority in Surrey, BC.

Hill agrees the hardest choices were whether to use emergency resources for cases that were not clearly urgent. "Say a patient had a chest x-ray that was fuzzy and needed a [CT people with AIDS by the end of 2005;

- Legislation that would decriminalize marijuana died on the order paper when Martin called the federal election. A new government would have to re-introduce another bill. Separate regulations to ease restrictions on medicinal marijuana will still proceed;

- The Winnipeg arm of the new Public Health Agency will handle infectious disease control and epidemiology; the Ottawa offices will work on emergency planning and efforts to reduce the burden of chronic disease. - Laura Eggertson, CMAJ

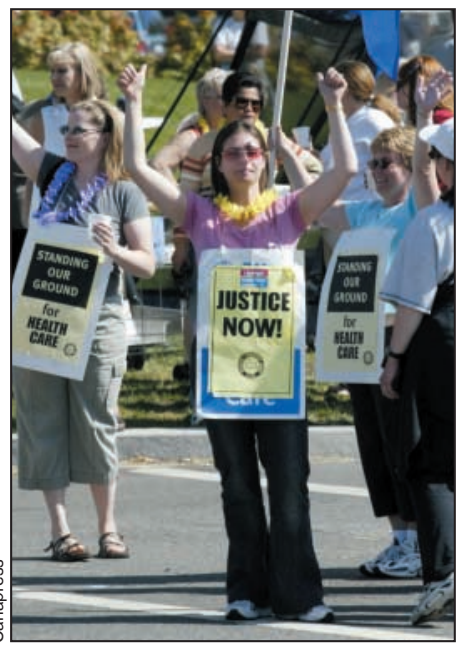

Strike out: 40000 BC workers were forced back to work.

scan]. What do you do with that?" he asks.

During the strike, Hill said stress reached a new level of frustration. That frustration level is expected to remain high as the health care systems struggle to catch up. King is philosophical. Newfoundlanders "are a hardy bunch and are used to delays," she says. "That helped patients and physicians survive." - Deborab fones, Vancouver, BC 